\title{
Antibody response to outer-membrane antigens of Pseudomonas aeruginosa in human burn wound infection
}

\author{
KATHRYN H. WARD, H. ANWAR*, M. R. W. BROWN , J. WALE $\ddagger$ and J. GOWAR
}

Microbiology Research Group, Pharmaceutical Sciences Institute, Department of Pharmaceutical Sciences, Aston University, Aston Triangle, Birmingham B4 7ET, "Department of Microbiology, University of Alberta, Edmonton, Alberta, Canada T6G $2 E 9$ and $¥ B$ urns Unit, Accident Hospital, Birmingham B 156 NA

\begin{abstract}
Summary. There is little information about the local and systemic antibody response to surface antigens of bacteria growing in situ in infected lesions in man. In this study, Pseudomonas aeruginosa was obtained directly from the infected wounds of two patients with burns and studied without subculture. Outer-membrane proteins (OMPs) were investigated and compared with those of cells cultivated in the laboratory, with the aim of selecting defined growth conditions to give surface antigens more closely resembling those found in vivo. Several high-mol. wt $(77000$ $101000)$ proteins were expressed in the outer membranes of the bacteria from the patients and could be phenotypically induced by cultivating the same isolate in irondepleted conditions in vitro. Other major OMPs (D, E, F, G and $\mathrm{H})$ were also observed in cells taken from the lesions. Immunoblotting demonstrated that proteins $\mathrm{D}$ and $\mathrm{E}$ were recognised by different classes of immunoglobulins in the sera of both patients as was flagellar antigen present in the outer-membrane preparation of the $P$. aeruginosa from patient 1 . Iron-regulated membrane proteins (IRMPs) were similarly detected, but more strongly by IgM from patient 1 . Furthermore, a marked antibody response to IRMPs was noted at the site of infection. Bands of a similar intensity were seen after absorption of the sera with lipopolysaccharide (LPS) purified from the infecting strain. This indicated that the response observed was directed against OMPs (including IRMPs) and not against contaminating LPS.
\end{abstract}

\section{Introduction}

Infection is the most frequent cause of morbidity and mortality in the severely burned patient (Pruitt et al., 1983). The burn site remains relatively sterile during the first $24 \mathrm{~h}$; thereafter, colonisation of the wound by gram-negative bacteria is common (Pruitt et al., 1983). Pseudomonas aeruginosa has emerged as a predominant member of the burn-wound flora and, in the USA, in the absence of topical therapy, is cultured from the burn injuries of $70 \%$ of patients by the third week (Pruitt, 1974).

For invasive infection to occur, the microorganisms must multiply to a population sufficient to mount a successful attack on the host. Severe thermal injury destroys the barrier function of the skin and this enables bacteria to gain easy access to the injured tissue. The denatured protein of the

Received 26 Jan. 1988; revised version accepted 8 May 1988. $\uparrow$ Correspondence should be sent to Professor M. R. W. Brown. burn eschar provides a good environment for microbial growth and the avascularity of the burn wound partly shields the micro-organisms from host defence mechanisms (Order et al., 1965).

The surface composition of bacteria plays an important role in pathogenicity (Smith, 1977; Costerton et al., 1979) and the expression of bacterial surface components is influenced by the environment in which they grow (Holme, 1972; Brown and Williams, 1985a, $b$ ). Growth rate and specific nutrient deprivation have gross effects on sensitivity to host defences (Finch and Brown, 1978; Brown and Williams, 1985a, b). Restricting the availability of iron is an important non-specific defence mechanism against bacterial infection (Weinberg, 1978, 1984; Bullen, 1981; Griffiths, 1983). The freely available iron concentration in body fluids is extremely low $\left(c .10^{-18} \mathrm{M}\right)$ because of the presence of biological iron-chelating molecules such as transferrin and lactoferrin which have a high affinity for iron (Weinberg, 1978; Griffiths, 
1983). The bacteria respond to these conditions by synthesising their own iron-scavenging compounds (siderophores) which have an even higher affinity for iron (Neilands, 1974), and also by expression of high-mol. wt iron-regulated membrane proteins (IRMPs) in the outer membrane (OM) which function as receptors for iron-siderophore complexes (Neilands, 1974; Griffiths, 1987).

Preliminary investigations (Anwar et al., 1985) of a burn patient during the acute phase of $P$. aeruginosa wound infection indicated the presence of serum IgG antibodies to outer-membrane proteins (OMPs) including the IRMPs. In the present study, we investigated the OMP antigens of $P$. aeruginosa taken directly from infected wound tissue and studied the patients' immune responses to these antigens as they occurred naturally in infection.

\section{Materials and methods}

\section{Collection and identification of bacteria}

Skin samples (c. $100 \mathrm{~g}$ containing $c .10^{9}$ bacteria) were collected from two patients with severe burn injuries. The samples were collected after wound excision about 1 week after signs of colonisation. Microbiological analysis indicated that $P$. aeruginosa was the sole infecting organism in the burn wounds of patient 1 and the predominant isolate from patient 2. Klebsiella pneumoniae was also isolated from the second patient but only as a minor contaminant. $P$. aeruginosa strains were $\mathrm{O}$ serotyped by Dr T. Pitt (Central Public Health Laboratory, Colindale, London). Serotype $\mathrm{O} 4$ was isolated from patient 1 and serotype $\mathrm{O} 6$ from patient 2 . Saline $(\mathrm{NaCl}$ $0.85 \% \mathrm{w} / \mathrm{v}, 100 \mathrm{ml}$ ) was added to the skin sample which was vigorously blended for $60 \mathrm{~s}$. This was followed by coarse filtration to remove cell debris. Material retained by the filter was washed twice with saline and the filtered washings added to the bulked filtrate. The bacteria were harvested by centrifugation at $5000 \mathrm{~g}$ for $10 \mathrm{~min}$ and washed twice with saline. The pellet which contained the bacteria was resuspended in distilled water and OMs then prepared. The filtrate supernate, designated as infected tissue fluid, was lysophilised and resuspended in $100 \mathrm{ml}$ of $10 \mathrm{~mm}$ Tris $-\mathrm{HCl}$ in $\mathrm{NaCl} 0.85 \%$ w/v, $\mathrm{pH} 7.4$ (TBS) containing Tween $200.075 \% \mathrm{v} / \mathrm{v}$ (TBS-Tween) and stored at $-20^{\circ} \mathrm{C}$ for immunoblotting.

Clinical strains of Serratia marcescens, Escherichia coli, $K$. pneumoniae and Proteus mirabilis, as described by Shand et al. (1985), were also included in this study.

\section{Cultivation of bacteria}

Bacteria were cultivated in iron-depleted tryptone soy broth (TSB $-\mathrm{Fe}$ ) and iron-sufficient tryptone soy broth (TSB $+\mathrm{Fe})$ as described by Kadurugamuwa et al. (1987).
Bacteria were grown overnight in an orbital shaking incubator, harvested by centrifugation at $5000 \mathrm{~g}$ for $10 \mathrm{~min}$ and washed once with saline.

\section{Outer-membrane preparation}

The bacterial pellet was resuspended in $20 \mathrm{ml}$ of distilled water and broken by $10 \times 60$-s pulses of sonication in an ice bath, with 60-s intervals for cooling. Unbroken cells were removed by centrifugation at $5000 \mathrm{~g}$ for $10 \mathrm{~min}$. Sarkosyl (N-lauryl sarcosinate, sodium salt; Sigma) was added to the supernate to a final concentration of $2 \% \mathrm{w} / \mathrm{v}$. The mixture was incubated for $30 \mathrm{~min}$ at room temperature and then centrifuged at $38000 \mathrm{~g}$ for $1 \mathrm{~h}$ (Filip et al., 1973). The outer-membrane pellets were washed twice with distilled water and stored at $-20^{\circ} \mathrm{C}$.

\section{Sodium dodecyl sulphate-polyacrylamide gel electrophoresis (SDS-PAGE)}

Membrane preparations were subjected to SDS-PAGE by the system described by Lugtenberg et al. (1975) as modified by Anwar et al. (1983) with $14 \% \mathrm{w} / \mathrm{v}$ acrylamide gels and specially purified SDS (BDH, Poole). Each lane was loaded with $c .50 \mu \mathrm{g}$ of protein. Separated OMPs were either stained with Coomassie blue R-250 0.1\% w/v or used for immunoblotting. OMPs were labelled according to the convention of Mizuno and Kageyama (1978) as modified by Hancock and Carey (1979).

\section{Isolation of flagella}

Flagellar preparations were isolated by a modification of the method of Montie et al. (1982). Bacterial culture $(2 \mathrm{~L})$, grown for $48 \mathrm{~h}$ in TSB $+\mathrm{Fe}$ in a slowly rotating orbital incubator at $37^{\circ} \mathrm{C}$, was harvested by centrifugation at $5000 \mathrm{~g}$ for $10 \mathrm{~min}$. The cells were resuspended in $20 \mathrm{ml}$ of saline and blended vigorously for $10 \mathrm{~s}$ to shear the flagella. Flagella were isolated by a process of differential centrifugation as follows: after blending, the suspension was centrifuged at $5000 \mathrm{~g}$ for $10 \mathrm{~min}$ to remove whole cells and the supernate centrifuged at $100000 \mathrm{~g}$ for $4 \mathrm{~h}$ to precipitate the flagella. This procedure was repeated until a clear pellet was obtained. SDS-PAGE was used to determine the purity of the preparation and this gave a single band after staining with Coomassie blue.

\section{Extraction of LPS}

Lipopolysaccharide (LPS) was extracted by the hot phenol-water method of Westphal and Jann (1965).

\section{Immunoblotting}

OMPs separated on polyacrylamide gels were transferred to nitrocellulose (NC) paper and antigenic sites visualised by a modification of the method of Towbin $e t$ al. (1979). The NC paper was first incubated in TBS- 
Tween for $30 \mathrm{~min}$ to saturate non-specific binding sites. This was followed by incubation with patient's serum diluted 1 in 20 in TBS-Tween, or with infected tissue fluid, for $4 \mathrm{~h}$ at $37^{\circ} \mathrm{C}$ and overnight at $4^{\circ} \mathrm{C}$. The $\mathrm{NC}$ paper was washed thoroughly with TBS and incubated for a further $2 \mathrm{~h}$ at $37^{\circ} \mathrm{C}$ with horseradish peroxidase-goat anti-human IgG, IgM or IgA conjugate (Miles-Yeda, Rehovot, Israel) diluted 1 in 2000 in TBS-Tween. After incubation, the $\mathrm{NC}$ paper was again washed thoroughly and the bands were visualised with a solution containing 4-chloro-1-naphthol $25 \mu \mathrm{g} / \mathrm{ml}$ and $\mathrm{H}_{2} \mathrm{O}_{2} 0.01 \% \mathrm{v} / \mathrm{v}$ in TBS. As a control, replicate NC transfers were stained with amido black $1 \% \mathrm{w} / \mathrm{v}$ in methanol $10 \% \mathrm{v} / \mathrm{v}$ and acetic acid $7 \% \mathrm{v} / \mathrm{v}$ to show qualitative transfer of all proteins from the acrylamide gel to the NC paper; these NC replicates were used to identify the protein bands.

\section{Serum}

Patient's serum was separated from blood obtained by venepuncture during the course of clinical investigation. A small portion of blood was allowed to clot at $37^{\circ} \mathrm{C}$ for $2 \mathrm{~h}$ then centrifuged at $2000 \mathrm{~g}$ for $10 \mathrm{~min}$ and the serum collected and stored at $-20^{\circ} \mathrm{C}$.

\section{Absorption of serum with LPS}

Undiluted serum $(1 \mathrm{ml})$ was mixed with LPS $2 \mathrm{mg}$ extracted from the infecting strain of $P$. aeruginosa and incubated for $1 \mathrm{~h}$ at $37^{\circ} \mathrm{C}$ followed by $18 \mathrm{~h}$ at $4^{\circ} \mathrm{C}$. Precipitated immune complexes were pelleted by centrifugation at $5000 \mathrm{~g}$ for $15 \mathrm{~min}$. The supernatant serum was removed and re-absorbed with an additional $2 \mathrm{mg}$ of LPS as above.

\section{Results}

\section{Analysis of P. aeruginosa $O M P$ s}

Fig. 1 shows the SDS-PAGE OMP profiles of $P$. aeruginosa obtained directly from patient 1 (lane 3 ) and the same isolate grown in TSB - Fe (lane 2) and TSB + Fe (lane 1). Several high-mol. wt OMPs (77 000-101000) known as iron-regulated membrane proteins (IRMPs) were strongly induced in the OM of cells grown in TSB - Fe (lane 2). The expression of these proteins was also observed in the OM of bacterial cells taken directly without subculture from the burn wound (lane 3 ) but they were barely detectable in the OM of the same strain cultivated in TSB + Fe (lane 1). Proteins D, E, F, $\mathrm{G}, \mathrm{H}$ and $\mathrm{I}$ were apparent in all three lanes but minor differences between cells taken from the wounds and cells grown in TSB - Fe were noted. An additional protein band (mol. wt $c .55000$ ) just above band $\mathrm{D}$ was observed in the $\mathrm{OM}$ preparation of bacteria taken directly from the wound (lane 3)

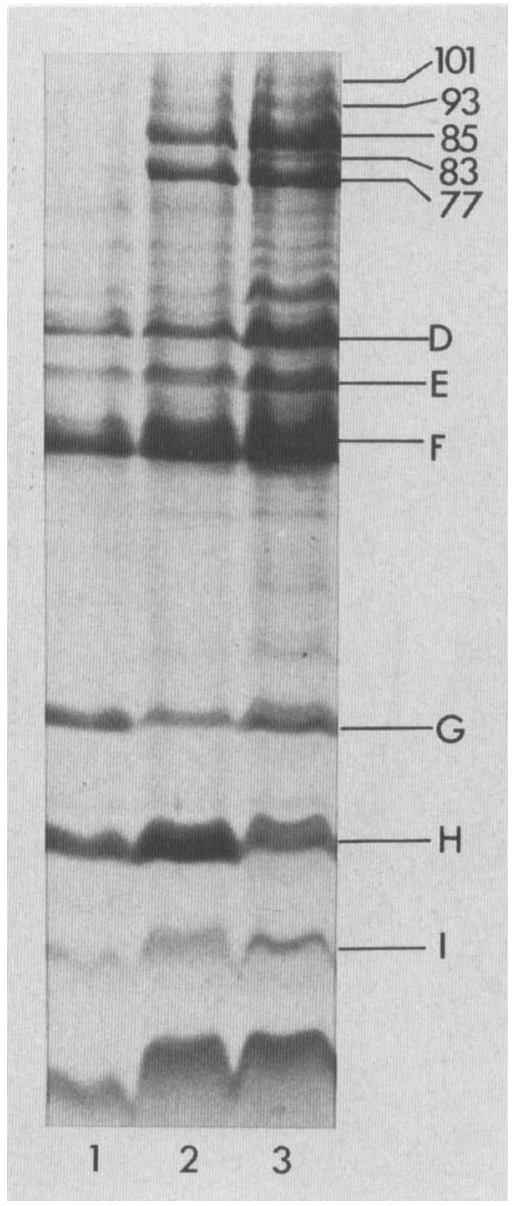

Fig. 1. SDS-PAGE of OMPs of P. aeruginosa taken directly from the infected wound tissue of patient 1 (lane 3 ) and of the same isolate cultivated in TSB $-\mathrm{Fe}$ (lane 2 ) or TSB $+\mathrm{Fe}$ (lane 1 ). OMPs were stained with Coomassie blue and labelled according to the convention of Mizuno and Kageyama (1978). Numbers refer to mol. wts $\left(10^{3}\right)$.

and, weakly, in OMs from bacteria grown in vitro (lanes 1 and 2). Closely similar results were obtained with $P$. aeruginosa from patient 2 (data not shown).

\section{Antibody response to $P$. aeruginosa $O M P S$}

The OMP antigens separated by SDS-PAGE (fig. 1) were electrophoretically transferred to NC paper and qualitative transfer of protein bands was confirmed by staining with amido black (not shown). Replicate immunoblots were allowed to react with antibodies present either in the serum or in wound tissue fluid.

Fig. 2a shows those antigens of $P$. aeruginosa recognised by IgM antibodies in the serum of the 


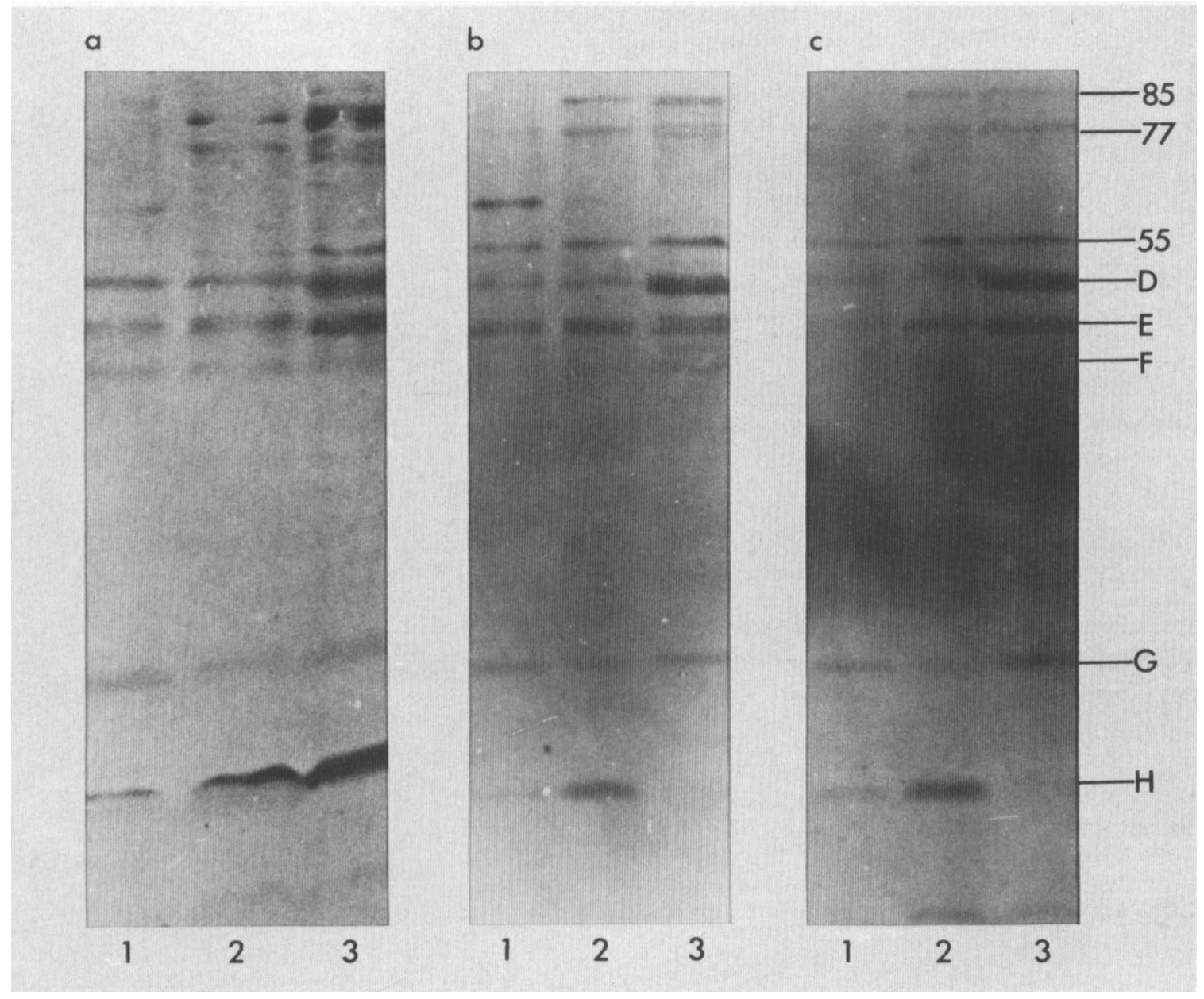

Fig. 2. Immunoblots of the OMPs in fig. 1 (lanes 1-3 as described), electrophoretically transferred to NC paper and probed with serum from patient 1 , obtained 1 week after onset of infection. Reactions were visualised with peroxidase-labelled anti-human (a) $\operatorname{IgM}$ (b) IgG and (c) IgA.

first patient, 1 week after initial signs of infection. IRMPs (predominantly the 77000 - and 85000 mol. wt proteins) were detected in $P$. aeruginosa grown in vitro in conditions of iron-depletion (lane 2) or taken directly from the burn wound (lane 3), more strongly in the latter case. There was no recognition of such proteins in cells grown in ironplentiful conditions (lane 1). Furthermore, a response to proteins $\mathrm{D}, \mathrm{E}$ and $\mathrm{H}$ in all three lanes was noted along with the $55000-\mathrm{mol}$. wt antigen in lane 3 , but $F$ and $G$ were detected only faintly. Serum samples obtained in subsequent weeks gave similar patterns of response (data not shown). Serum IgG antibodies (fig. 2b) also detected IRMPs although to a lesser degree than did the IgM. Serum IgG antibodies additionally detected proteins $\mathrm{D}$ and $\mathrm{E}$, but the response to porin protein $\mathrm{F}$ was again weak.
There was a stronger reaction with the 55000 mol. wt antigen in all three lanes. Protein $\mathrm{H}$ was recognised in the OM of cells grown in vitro (lanes 1 and 2), particularly in the iron-depleted cells (lane 2) but there appeared to be no corresponding reaction to the protein in the OM preparation of cells taken from the burns (lane 3 ). The IgA response (fig. 2c) was similar to that seen with IgG (fig. 2b); antibodies were directed against IRMPs, the $55000-\mathrm{mol}$. wt antigen and proteins D and E. Protein $\mathrm{H}$ was again detected only in the OMs of cells grown in vitro (lanes 1 and 2) and not in the OM of cells taken from the burns (lane 3 ).

Fig. 3 represents an immunoblot of flagellin protein purified from $P$. aeruginosa (lane 2 ); it migrated as a single band and was recognised strongly by serum antibodies. Furthermore, it was 


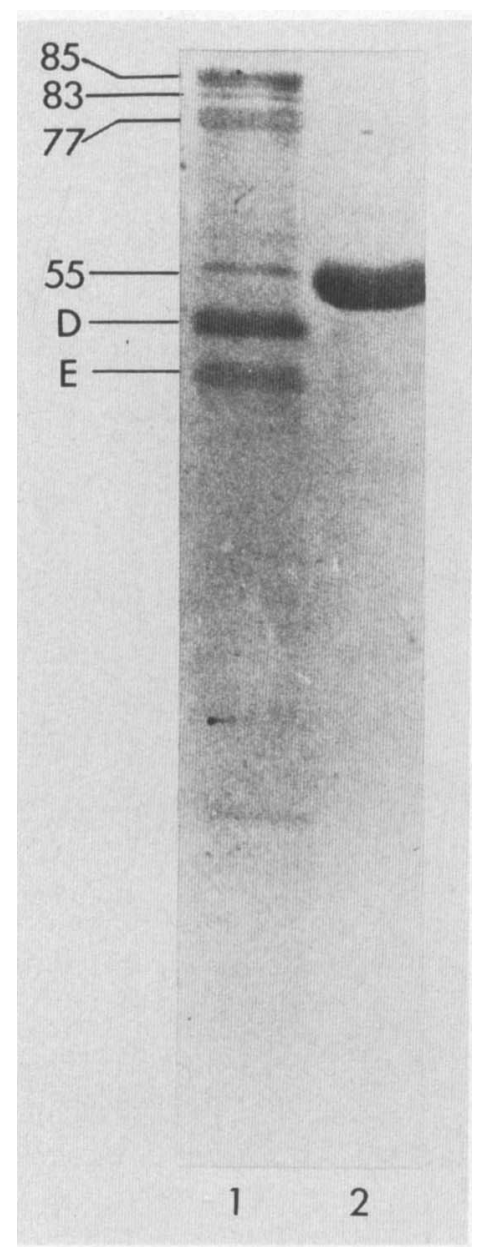

Fig. 3. Immunoblot of purified flagella (lane 2) and OMPs of $P$. aeruginosa taken directly from burn wounds (lane 1) electrophoretically transferred to NC paper and probed with serum from patient 1 . The reaction was visualised with peroxidase-labelled anti-human $\operatorname{IgA}$.

seen to co-electrophorese with the 55000 -mol. wt protein present in the OM preparations, suggesting the possible identity of this antigen. The band in question was not as distinct in the Coomassie bluestained gel (fig. 1), presumably because the amount of flagellin present was below the sensitivity of the protein stain.

Fig. 4a shows the OMP profiles of $S$. marcescens (lane 1), E. coli (lane 2), K. pneumoniae (lane 3), $P$. mirabilis (lane 4) and $P$. aeruginosa (lane 5) transferred to NC paper and stained with amido black. The organisms were grown in TSB $-\mathrm{Fe}$ and IRMPs were expressed in all except $S$. marcescens (lane 1). When the separated OM antigens of these five gram-negative bacteria were incubated with serum from patient 1 , a very strong $\mathrm{IgG}$ response to the surface antigens of the Enterobacteriaceae was observed, including the rough LPS of these organisms which ran at the front of the gel (fig. $4 \mathrm{~b}$, lanes 1 to 4$)$. However, the reaction with $P$. aeruginosa $\mathrm{OM}$ antigens was much less intense, which probably reflects the acute stage of infection with this organism. Pre-infection serum was not available for us to investigate the immune status of this patient before colonisation with $P$. aeruginosa.

The presence of immunoglobulins at the site of infection was investigated by incubating the separated OMPs shown in fig. 1 with tissue fluid from the wound from which the bacteria were isolated (figs. 5a, b and c). The IgG response (fig. 5b) reflected the results obtained with serum (fig. 3b). IgM (fig. 5a) and IgA (fig. 5c) antibodies present in the tissue fluid were predominantly directed against the IRMPs of $P$. aeruginosa with only a faint recognition of proteins $\mathrm{D}$ and $\mathrm{E}$.

The serum antibody response of patient 2 was investigated with the separated OMPs of the bacteria isolated from this patient $-K$. pneumoniae and $P$. aeruginosa. Each isolate was cultivated in vitro and OMs were prepared but the OMP profile obtained with the $K$. pneumoniae isolate bore no resemblance to the OM preparation from organisms taken directly from the wound. Therefore, it was considered that the low concentration of the contaminating organisms did not contribute significantly to the $P$. aeruginosa profile observed. However, it is not known whether the co-existence of other pathogens at the site of infection affects the expression of surface antigens of $P$. aeruginosa.

The OMP profile of the $P$. aeruginosa strain from patient 2 was identical to those observed with the strain from patient 1 (data not shown) and again demonstrated the expression of IRMPs by bacteria taken directly from the burn wounds. Fig. 6a (i) and (ii) shows the $\operatorname{IgG}$ response of patient 2 to $P$. aeruginosa antigens at 1 and 3 weeks after the first signs of infection. IRMPs, again especially the $77000-$ and $85000-\mathrm{mol}$. wt proteins, were recognised by IgG (fig. 6a, i and ii, lanes 2 and 3 ). There was also a reaction with proteins $D$ and $E$ and $a$ significant increase in the recognition of protein $F$ by the second week after onset of infection (fig. 6a, ii). The latter may indicate the reaction of antibody with non-conformational epitopes of protein $F$ (Mutharia and Hancock, 1985). A band below protein $\mathrm{F}$ is believed to be partly undenatured form of this protein as described by Hancock and Carey (1979). As with patient 1, IgG antibodies recognised protein $\mathrm{H}$ only in $\mathrm{OM}$ preparations from cells grown in vitro and not in those for cells taken directly from the burn wound (lanes 2 and 3 ). A 


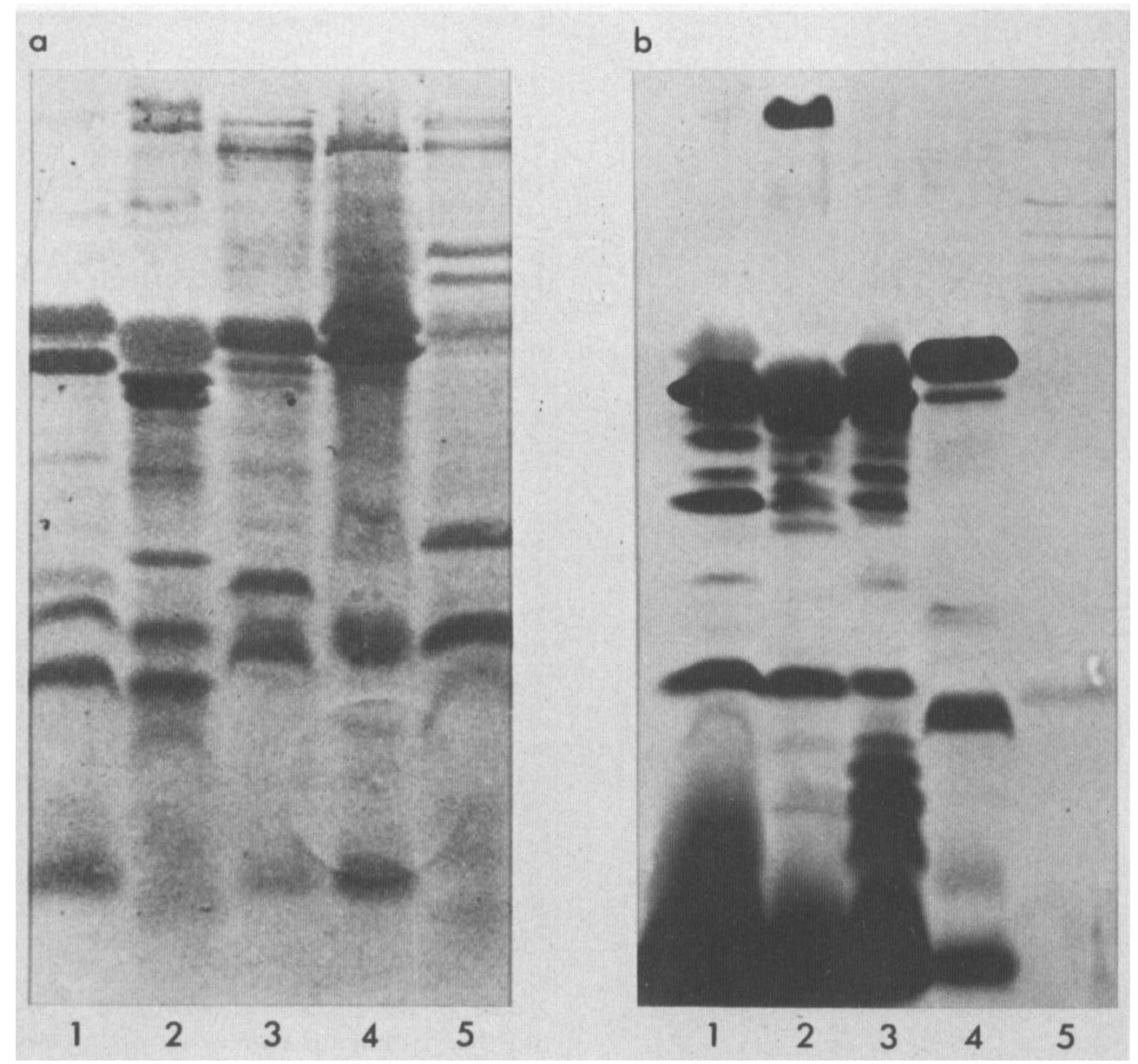

Fig. 4. OMPs of $S$. marcescens (lane 1), E. coli (lane 2), K. pneumoniae (lane 3), $P$. mirabilis (lane 4) and $P$. aeruginosa (lane 5) cultivated in TSB - Fe. OMPs were electrophoretically transferred to NC paper and (a) stained with amido black $1 \% \mathrm{w} / \mathrm{v}$, or (b) probed with serum from patient 1 and the reaction visualised with peroxidase-labelled anti-human IgG.

protein above D was observed in the OM of cells directly taken from the burn wound tissue (lane 3) but was barely detectable in the OM of cells grown in vitro (lanes 1 and 2 ).

IRMPs and proteins $\mathrm{D}$ and $\mathrm{E}$ elicited $\operatorname{IgA}$ antibody formation (fig. 6b) and, similarly, a band above protein $\mathrm{D}$ was recognised in OM preparations of cells taken directly from the burn wound (lane 3 ). This band appeared to have an electrophoretic mobility different from that of the flagella purified from the isolate. A marked response was noted to protein $\mathrm{H}$ in OM preparations from cells cultivated in vitro (lanes 1 and 2 ). Indeed these represented the most intense bands on the immunoblot. No major difference in response was observed in immunoblots with subsequent serum samples (data not shown).
A very weak IgM response was obtained with the serum of this patient; it was too faint to be photographed. The IgG response locally at the wound site (data not shown) was indistinguishable from that found with serum (fig. 6a).

To confirm that the immunoblotting results represented binding of antibodies to the OMPs, immunoglobulins against LPS were removed from patients' serum samples by immunoprecipitation after addition of LPS purified from the appropriate strain cultivated in vitro (Westphal and Jann, 1965). Probing immunoblots of separated LPS with untreated serum revealed a faint ladder pattern (fig. 7 , lane 1) which was not observed on probing with the LPS-absorbed serum (fig. 7, lane 2). However, when the same two sera were allowed to react with 


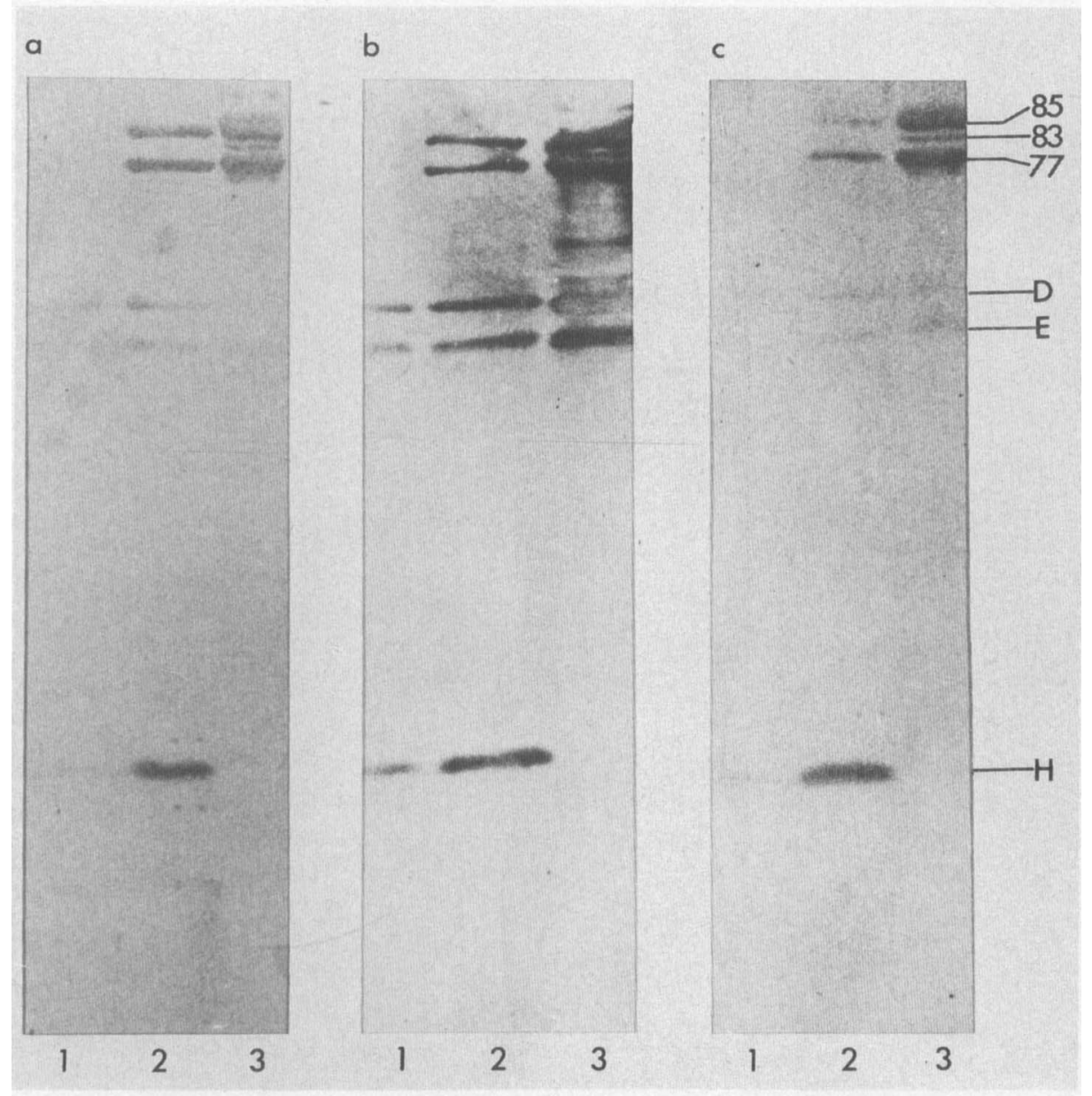

Fig. 5. Immunoblot of the OMPs in fig. 1 (lanes $1-3$ as described) electrophoretically transferred to NC paper and probed with infected tissue fluid from patient 1. Reactions were visualised with peroxidase-labelled anti-human (a) $\operatorname{lgM}$ (b) $\operatorname{IgG}$ and (c) $\operatorname{IgA}$.

replicate OMP immunoblots, identical patterns and intensities of banding were seen (fig. 7, lanes 3 and 4 respectively).

\section{Discussion}

Information concerning properties of bacteria in situ in infection sites, especially in burn wounds, is generally lacking. Hypotheses about the behaviour of micro-organisms in human infections have been extrapolated from studies with bacteria cultivated in vitro. Such results may be misleading because the surface characteristics of bacteria grown in vitro may not represent those infecting burn wounds (Brown and Williams, 1985a, $b$ ). The results of this investigation clearly indicated that $P$. aeruginosa was growing under iron-restricted conditions in the infected burn wounds of two patients, as judged by the expression of IRMPs in the OM of bacteria obtained directly from the wound. Similar observations have been reported in infections in cystic fibrosis patients (Brown et al., 1984), in urinary tract infections in man (Lam et al., 1984; Shand et $a l ., 1985)$ and in experimentally induced infections in animals (Griffiths et al., 1983; Sciortino and Finkelstein, 1983; Cochrane et al., 1987). Preliminary data also indicated that, for patient 1 , bacteria taken directly from the wounds displayed altered LPS profiles when compared to their counterparts grown in vitro (results not shown), as has been shown by Cochrane et al. (1988).

The IRMP antigens expressed in vivo and in vitro in iron-depleted conditions were recognised by antibodies present in serum taken early in the 


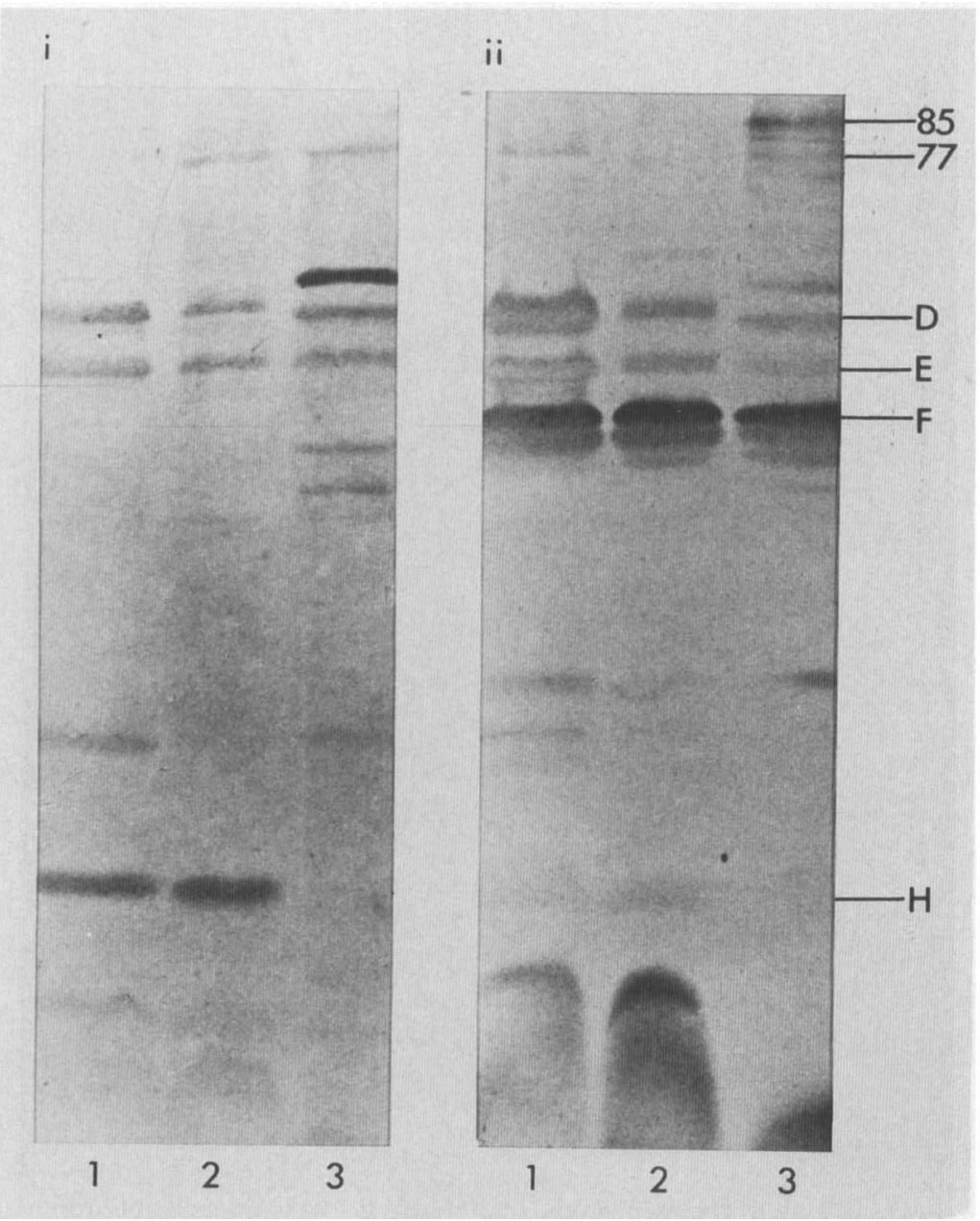

b

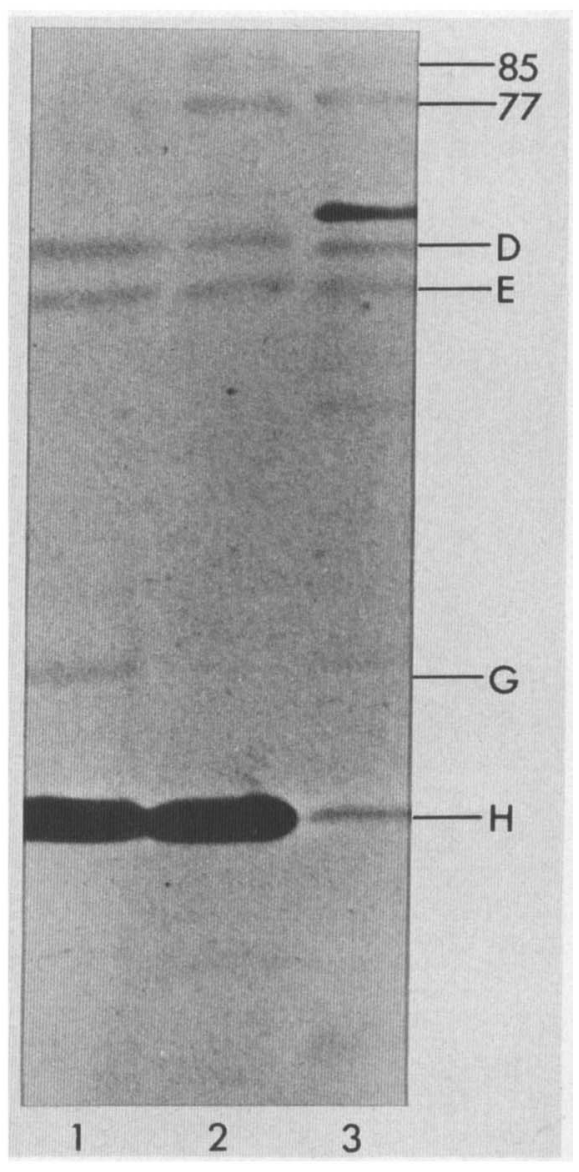

Fig. 6. OMPs of $P$. aeruginosa isolated directly from the infected wound tissue of patient 2 (lane 3 ) and of the same isolate cultivated in TSB - Fe (lane 2) and TSB + Fe (lane 1). OMPs were electrophoretically transferred to NC paper and probed with serum from patient 2 obtained (i) 1 week and (ii) 3 weeks after onset of infection. Reactions were visualised with peroxidase-labelled antihuman (a) IgG or (b) IgA. With IgA, there was no difference between the reactions with serum collected 1 week or 3 weeks after onset of infection.

infection and also locally in wound tissue. $P$. aeruginosa produces iron-chelating compounds such as pyochelin and pyoverdin in iron-depleted conditions in vitro (Cox et al., 1981; Cox and Adams, 1985). However, it is not known which of the IRMPs function as receptors for iron-siderophore complexes. The production of antibodies against these antigens may hinder the uptake of iron and, therefore, reduce the growth rate of the organism in vivo. Antibodies of all three classes of immunoglobulins were shown to be directed against the IRMPs, indicating their importance as targets of host defences. The iron-restricted nature of the wound site may have further implications because there is a significant rise in the production of toxin
A by $P$. aeruginosa in iron-depleted conditions (Bjorn et al., 1978).

Furthermore, immunoblotting demonstrated recognition of proteins D, E and $\mathrm{H}$, as well as flagellar protein, by serum antibodies. The latter antigen has been shown to be highly immunogenic in other studies (Mutharia et al., 1982; Anwar et al., 1984). Motility is thought to be an important virulence factor in burn-wound sepsis (Holder, 1985) and antibodies which inhibit the functioning flagellum are likely to reduce the invasive capacity of the organism. The efficacy of a divalent flagellar preparation as a vaccine has been tested in a burned mouse model (Holder and Naglich, 1986). Protection was afforded against live $P$. aeruginosa in the 


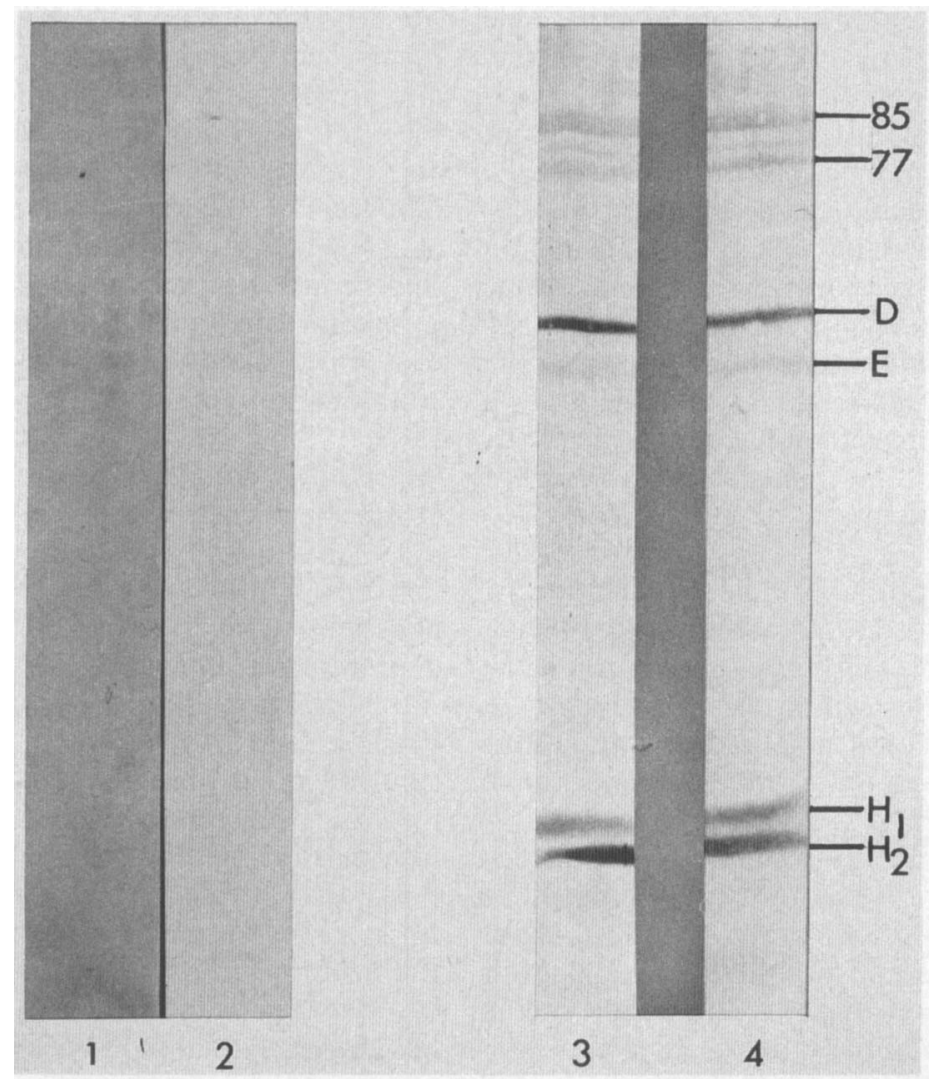

Fig. 7. Immunoblot of LPS (lanes 1 and 2) and OMPs (lanes 3 and 4) of $P$. aeruginosa cultivated in TSB - Fe, probed with untreated patient's serum (lanes 1 and 3) and LPS-absorbed serum (lanes 2 and 4). The reaction was visualised with peroxidase-labelled antihuman $\operatorname{IgG.}$

burn area and was independent of both the flagellar and somatic antigen of the challenge strain.

The OMPs of $P$. aeruginosa used in these immunoblotting studies had been treated with SDS and 2-mercaptoethanol. Conformational epitopes in the antigens may have been affected by this treatment which could explain the low level of recognition of protein F (Mutharia and Hancock, 1985). This should be explored further with monospecific monoclonal antibodies.

The lack of immunological recognition of protein $\mathrm{H}$ in OMs of cells taken directly from burns may suggest that the method of preparation caused loss of antigenicity of protein $\mathrm{H}$ in these OMs. Possibly there is competition for the antigenic binding sites between other classes of immunoglobulin such as IgM (fig. 2a, lane 3). Further work is needed to study the binding of immunoglobulins to protein $\mathbf{H}$ molecules. In addition, it is not clear whether the response observed to the protein of cells grown in vitro is to $\mathrm{H}_{1}$ or $\mathrm{H}_{2}$ as described by Hancock and
Carey (1979) because the individual proteins were not separated in the system used here (Anwar et al., 1983).

The strong IgG response to Enterobacteriaceae surface antigens (fig. 4) is to be expected since these bacteria are all common members of the gut flora. Furthermore, despite possible post-burn immunosuppression, there were still sufficient circulatory immunoglobulins present to react with the OM antigens of the Enterobacteriaceae. In a previous study we showed that antibodies in serum from volunteers with no previous history of pseudomonas infection reacted strongly with enterobacterial antigens but not with pseudomonal antigens (Anwar et al., 1985). This suggests that there is little cross-reactivity between the two bacterial families and that the level of antibodies to $P$. aeruginosa in the population is low except following infection with the organism.

The band above protein $\mathrm{D}$ recognised in OM preparations of cells taken directly from the burn 
wound (fig. 2) is interesting. Its expression may be related to surface growth of the organisms in the burn wound or to the influence of other environmental factors. The identity of this band remains to be investigated by monoclonal antibody. The $P$. aeruginosa strains isolated from the two patients possessed different flagellar types and absence of flagella in the OM preparation obtained from bacteria grown in vivo in patient 2 may reflect shearing and loss of this antigen during sonication.

The humoral immune response to OMPs of $P$. aeruginosa has been investigated following subcutaneous infection in mice (Hedstrom et al., 1984) and the results showed production of antibodies to proteins $\mathrm{F}, \mathrm{H}_{2}$ and $\mathrm{I}$. The different picture observed in our investigation probably reflects variation in the immunological response of man and mouse. Furthermore, bacteria cultivated under iron-sufficient conditions were used in their study so the response to IRMPs could not be determined and serum was not obtained until 14 days after onset of infection.

Sera from cystic fibrosis patients with pseudomonas lung infection has also been used in immunoblotting studies (Anwar et al., 1984). Such sera detected IRMPs and proteins $\mathrm{D}$ and $\mathrm{H}_{2}$ and showed a particularly strong reaction with proteins $\mathrm{F}$ and $\mathrm{G}$. In addition, a band below $\mathrm{H}_{2}$ which was postulated as representing rough LPS had stimulated a marked response. Strong recognition of this antigen or of proteins $F$ and $G$ was not observed with the burn patients in this investigation. In cystic fibrosis, $P$. aeruginosa causes a chronic infection which may persist for upwards of 20 years. The bacteria grow in glycocalyx-enclosed micro-colonies embedded in exopolysaccharide and mobile swarmer cells are frequently released resulting in exacerbation of pneumonia (Costerton et al., 1983). Over the years, $P$. aeruginosa exposes many of its antigens to the immune system, thus stimulating the production of high titres of antibodies to numerous bacterial components (Høiby and Axelsen, 1973). This is in contrast to $P$. aeruginosa in burn wounds which essentially produces an acute and possibly life-threatening infection, and thus a different immune response.

It has been reported that OMPs separated by SDS-PAGE and transferred to NC paper may be contaminated with co-migrating LPS (Poxton et al., 1985; Lam et al., 1987). Probing of replicate immunoblots of OMPs with patient's serum before and after absorption with purified LPS resulted in identical patterns and intensities of bands. The LPS was purified from cells cultivated in vitro because insufficient bacteria could be obtained from the burn wound for the extraction procedure. It is possible that if the LPS from bacteria taken directly from the burn wound and those grown in vitro differs, absorption of sera with the latter may not remove all the antibodies to the former. Nonetheless, the results suggested that the presence of LPS on the immunoblot did not contribute significantly to the bands observed.

Several papers have reported the induction of a protein of mol. wt 14000 in $P$. aeruginosa under conditions of iron-deprivation (Sokol and Woods, 1983, 1984, 1986; Sokol, 1984). The initial study (Sokol and Woods, 1983) relied on incubation of OM preparations with ${ }^{59} \mathrm{Fe}$-pyochelin followed by SDS-PAGE analysis. However, it is unlikely that the binding of ${ }^{59} \mathrm{Fe}$ to pyochelin or of ${ }^{59} \mathrm{Fe}$ pyochelin to receptor protein would withstand SDS denaturation unless the links between molecules were covalent. There is no evidence to suggest that this is so, and no SDS-PAGE gels of ${ }^{59} \mathrm{Fe}$-pyochelin running alone were shown. A $14000-\mathrm{mol}$. wt protein has been reported in periplasmic fractions of iron-deprived $P$. aeruginosa (Cox, 1985) and it is possible that this protein was demonstrated in the membrane fractions investigated. Alternatively, the protein in question may represent a fragment of a larger protein which binds ${ }^{59} \mathrm{Fe}$-pyochelin. We have investigated wild type and laboratory strains of $P$. aeruginosa of many serotypes and have never observed induction of a $14000-\mathrm{mol}$. wt protein under iron-deprived conditions (Anwar et al., 1984, 1985; Brown et al., 1984; Kadurugamuwa et al., 1987).

Commercial vaccines against $P$. aeruginosa based largely on LPS are available but are rarely used in clinical practice. This may be due partly to problems associated with their toxicity and serotype specificity (Pennington, 1979). In an attempt to overcome these problems some researchers have considered OMPs as immunotherapeutic agents, since they are non-toxic and are antigenically conserved among serotypes (Mutharia et al., 1982; Anwar et al., 1985). Gilleland et al. (1984) reported that antibodies to protein $\mathrm{F}$ offered protection against intraperitoneal challenge with laboratory strains of $P$. aeruginosa and, more recently, Matthews-Greer and Gilleland (1987) demonstrated protection with purified protein $F$ against challenge with six heterologous LPS Fisher-Devlin immunotypes in a burned mouse model. The ability of IRMPs and other major OMPs, individually or in combination, to protect animals against challenge with different serotypes of $P$. aeruginosa remains to be investigated. The information gained in this study will be useful in the rational design of vaccines so that 
protection of individuals with burns against infections caused by $P$. aeruginosa may be achieved.

\section{REFERENCES}

Anwar H, Brown M R W, Day A, Weller P H 1984 Outer membrane antigens of mucoid Pseudomonas aeruginosa isolated directly from the sputum of a cystic fibrosis patient. FEMS Microbiology Letters 24: 235-239.

Anwar H, Lambert P A, Brown M R W 1983 Influence of sodium dodecyl sulphate quality on the electrophoretic mobility of the outer membrane proteins of mucoid and non-mucoid Pseudomonas aeruginosa. Biochimica et Biophysica Acta 761 : 119-125.

Anwar H, Shand G H, Ward K H, Brown M R W, Alpar K E, Gowar J 1985 Antibody response to acute Pseudomonas aeruginosa infection in a burn wound. FEMS Microbiology Letters 29: 225-230.

Bjorn M J, Iglewski B H, Ives S K, Sadoff J C, Vasil M L 1978 Effect of iron on yields of exotoxin $A$ in cultures of Pseudomonas aeruginosa PA-103. Infection and Immunity 19: 785-791

Brown M R W, Anwar H, Lambert P A 1984 Evidence that mucoid Pseudomonas aeruginosa in the cystic fibrosis lung grows under iron-restricted conditions. FEMS Microbiology Letters 21 : 113-117.

Brown M R W, Williams P $1985 a$ Influence of substrate limitation and growth phase on sensitivity to antimicrobial agents. Journal of Antimicrobial Chemotherapy 15 Suppl: $7-$ 14.

Brown M R W, Williams P $1985 b$ The influence of environment on envelope properties affecting survival of bacteria in infections. Annual Reviews of Microbiology 39: 527-556.

Bullen J J 1981 The significance of iron in infection. Reviews of Infectious Diseases 3: 1127-1138.

Cochrane D M G, Anwar H, Brown M R W, Lam K, Costerton J W 1987 Iron deprivation in vivo: surface protein antigens of Pseudomonas aeruginosa in infection. Antibiotics and Chemotherapy 39: 125-135.

Cochrane D M G, Brown M R W, Weller P H 1988 Lipopolysaccharide antigens produced by Pseudomonas aeruginosa from cystic fibrosis lung infection. FEMS Microbiology Letters 50: 241-245.

Costerton J W, Brown M R W, Sturgess J M 1979 The cell envelope: its role in infection. In: Doggett $R$ G (ed) Pseudomonas aeruginosa: clinical manifestations of infection and current therapy. Academic Press, New York, pp $1-62$.

Costerton J W, Lam J, Lam K, Chan R 1983 The role of the microcolony mode of growth in the pathogenesis of Pseudomonas aeruginosa infections. Reviews of Infectious Diseases 5 Suppl: 867-873.

Cox C D 1985 Iron transport and serum resistance in Pseudomonas aeruginosa. Antibiotics and Chemotherapy 36: 1-12.

Cox C D, Adams P 1985 Siderophore activity of pyoverdin for Pseudomonas aeruginosa. Infection and Immunity 48: 130138.

Cox C D, Rinehart K L, Moore M L, Cook J C 1981 Pyochelin: novel structure of an iron chelating growth promoter for Pseudomonas aeruginosa. Proceedings of the National Academy of Sciences of the USA 78: 4256-4260.

Filip C, Fletcher G, Wulff J L, Earhart C F 1973 Solubilization of the cytoplasmic membrane of Escherichia coli by the ionic
This work was supported by grants from the Medical Research Council and the Cystic Fibrosis Research Trust, and these are gratefully acknowledged.

detergent sodium lauryl sarcosinate. Journal of Bacteriology 115: 717-722.

Finch J E, Brown M R W 1978 Effect of growth environment on Pseudomonas aeruginosa killing by rabbit polymorphonuclear leucocytes and cationic proteins. Infection and Immunity 20: 340-346.

Gilleland H E, Parker M G, Matthews J M, Berg R D 1984 Use of a purified outer membrane protein $F$ (porin) preparation of Pseudomonas aeruginosa as a protective vaccine in mice. Infection and Immunity $44: 49-54$.

Griffiths E 1983 Availability of iron and survival of bacteria in infection. In: Easmon C S F et al. (eds) Medical microbiology 3. Academic Press, London, pp 153-177.

Griffiths E 1987 The iron uptake systems of pathogenic bacteria. In: Bullen $\mathrm{J} J$, Griffiths $\mathrm{E}$ (eds) Iron and infection: molecular, physiological and clinical aspects. John Wiley and Sons, Chichester, pp 69-135.

Griffiths E, Stevenson P, Joyce P 1983 Pathogenic Escherichia coli express new outer membrane proteins when growing in vivo. FEMS Microbiology Letters 16: 95-99.

Hancock R E W, Carey A M 1979 Outer membrane of Pseudomonas aeruginosa: Heat- and 2-mercaptoethanolmodifiable proteins. Journal of Bacteriology 140: 902-910.

Hedstrom R C, Pavlovskis O R, Galloway D R 1984 Antibody response of infected mice to outer membrane proteins of Pseudomonas aeruginosa. Infection and Immunity 43: 49-53.

Høiby N, Axelsen N H 1973 Identification and quantitation of precipitins against Pseudomonas aeruginosa in patients with cystic fibrosis by means of crossed immunoelectrophoresis with intermediate gel. Acta Pathologica et Microbiologica Scandinavica 81B : 298-308.

Holder I A 1985 The pathogenesis of infections owing to Pseudomonas aeruginosa using the burned mouse model: experimental studies from the Shriners Burns Institute, Cincinnati. Canadian Journal of Microbiology 31 : 393-402.

Holder I A, Naglich J G 1986 Experimental studies of the pathogenesis of infections due to Pseudomonas aeruginosa: immunization using divalent flagella preparations. Journal of Trauma 26: 118-122.

Holme T 1972 Influence of environment on the content and composition of bacterial envelopes. Journal of Applied Chemistry and Biotechnology 22 : 391-399.

Kadurugamuwa J L, Anwar H, Brown M R W, Shand G H, Ward K H 1987 Media for study of growth kinetics and envelope properties of iron-deprived bacteria. Journal of Clinical Microbiology 25 : 849-855.

Lam C, Turnowski F, Schwarzinger E, Neruda W 1984 Bacteria recovered without subculture from infected human urines express iron-regulated membrane proteins. FEMS Microbiology Letters 24 : 255-259.

Lam J S, MacDonald L A, Lam M Y C, Duchesne L G M, Southam G G 1987 Production and characterization of monoclonal antibodies against serotype strains of Pseudomonas aeruginosa. Infection and Immunity 55: 1051-1057.

Lugtenberg B, Meijers J, Peters R, Van der Hoeck P, van Alphen L 1975 Electrophoretic resolution of the 'major outer membrane protein' of Escherichia coli K 12 into four bands. FEBS Letters 58 : 254-258.

Matthews-Greer J M, Gilleland H E 1987 Outer membrane protein F (porin) preparation of Pseudomonas aeruginosa as a protective vaccine against heterologous immunotype 
strains in a burned mouse model. Journal of Infectious Diseases 155: 1282-1291.

Mizuno T, Kageyama M 1978 Separation and characterization of the outer membrane of Pseudomonas aeruginosa. Journal of Biochemistry 84: 179-191.

Montie T C, Craven R C, Holder I A 1982 Flagellar preparations from Pseudomonas aeruginosa: isolation and characterization. Infection and Immunity 35: 281-288.

Mutharia L M, Hancock R E W 1985 Characterization of two surface-localized antigenic sites on porin protein $F$ of Pseudomonas aeruginosa. Canadian Journal of Microbiology 31 : $381-386$.

Mutharia L M, Nicas T I, Hancock R E W 1982 Outer membrane proteins of Pseudomonas aeruginosa serotype strains. Journal of Infectious Diseases 146: 770-779.

Neilands J B 1974 Iron and its role in microbial physiology. In : Neilands J B, Microbial iron metabolism; a comprehensive treatise. Academic Press, New York, pp 3-34.

Order S E, Mason A D, Switzer W E, Moncrief J 1965 Arterial vascular occlusion and devitalization of burn wounds. Annals of Surgery 161 : 502-508.

Pennington J E 1979 Immunotherapy of Pseudomonas aeruginosa infection. In: Doggett R G (ed) Pseudomonas aeruginosa: clinical manifestations of infection and current therapy. Academic Press, New York, pp 192-215.

Poxton I R, Bell G T, Barclay G R 1985 The association on SDS-polyacrylamide gels of lipopolysaccharide and outer membrane proteins of Pseudomonas aeruginosa as revealed by monoclonal antibodies and Western blotting. FEMS Microbiology Letters 27 : 247-251.

Pruitt B A 1974 Infections caused by Pseudomonas species in patients with burns and in other surgical patients. Journal of Infectious Diseases 130 Suppl: 8-13.

Pruitt B A, Lindberg R B, McManus W F, Mason A D 1983 Current approach to prevention and treatment of Pseudo- monas aeruginosa infection in burned patients. Reviews of Infectious Diseases 5 Suppl : 889-897.

Sciortino C V, Finkelstein R A 1983 Vibrio cholerae expresses iron-regulated membrane proteins in vivo. Infection and Immunity 42: 990-996.

Shand G H, Anwar H, Kadurugamuwa J, Brown M R W, Silverman S H, Melling J 1985 In vivo evidence that bacteria in urinary tract infection grow under iron-restricted conditions. Infection and Immunity 48 : 35-39.

Smith H 1977 Microbial surfaces in relation to pathogenicity. Bacteriological Reviews 41 : 475-500.

Sokol P A 1984 Production of the ferripyochelin outer membrane receptor by Pseudomonas species. FEMS Microbiology Letters 23 : 313-317.

Sokol P A, Woods D E 1983 Demonstration of an ironsiderophore-binding protein in the outer membrane of Pseudomonas aeruginosa. Infection and Immunity 40: 665669.

Sokol P A, Woods D E 1984 Antibody inhibition of ferripyochelin binding to Pseudomonas aeruginosa cell envelopes. Biochemistry 23: 5076-5080.

Sokol P A, Woods D E 1986 Characterization of antibody to the ferripyochelin-binding protein of Pseudomonas aeruginosa. Infection and Immunity 51 : 896-900.

Towbin H, Staehelin T, Gordon J 1979 Electrophoretic transfer of proteins from polyacrylamide gels to nitrocellulose sheets: procedure and some applications. Proceedings of the National Academy of Sciences of the USA 76: 4350-4354.

Weinberg E D 1978 Iron and infection. Microbiological Reviews 42: $45-66$.

Weinberg E D 1984 Iron withholding: a defense against infection and neoplasia. Physiological Reviews 64: 65-102.

Westphal O, Jann K 1965 Bacterial lipopolysaccharides. Extraction with phenol water and further applications of the procedure. In: Whistler R E (ed) Methods in carbohydrate chemistry V. Academic Press, New York, pp 83-91. 